\title{
Role of Stress-Related Brain-Derived Neurotrophic Factor (BDNF) in the Rat Submandibular Gland
}

\author{
Keiichi Tsukinoki $^{1}$ and Juri Saruta ${ }^{1}$ \\ ${ }^{1}$ Department of Environmental Pathology, Graduate School, Kanagawa Dental College, 82, Inaoka, Yokoshika, \\ Kanagawa 238-8580, Japan
}

Received May 2, 2012; accepted August 1, 2012; published online September 22, 2012

\begin{abstract}
The nerve growth factor (NGF) family comprises NGF, brain-derived neurotrophic factor (BDNF) and neurotrophins (NTs)-3, $-4 / 5,-6$ and -7 , all of which are collectively referred to as neurotrophins. However, the expression of neurotrophins other than NGF in the salivary gland has not been described in detail. Through interaction with the TrkB receptor, BDNF plays an important role in long-term potentiation. We found that BDNF expression increased within submandibular gland tissue in response to stress, suggesting that the salivary glands are sensitive to stress. In addition, stress caused increases in plasma BDNF derived from the submandibular gland and in TrkB receptor mRNA in the adrenal medulla. Plasma BDNF might activate TrkB receptors in the adrenal medulla during acute stress. The salivary glands are likely to influence not only oral health, but also systemic organs. This review addressed the relationship between hormone-like effects and stress-related BDNF expression in the rat submandibular gland.
\end{abstract}

Key words: brain-derived neurotrophic factor (BDNF), plasma, salivary gland, stress

\section{Introduction}

The exocrine salivary glands consist of the parotid, submandibular and sublingual glands as well as numerous minor salivary glands scattered in the oral cavity [39]. The salivary glands secrete saliva to digest food, promote mastication and fight bacteria [28]. However, the salivary glands might also play other important roles because they produce many substances [38]. Salivary products are associated with the maintenance of oral health, which is associated with systemic health, including that of the respiratory tract [43]. Not only the volume, but also the quality of saliva is considered important for good oral health (Fig. 1, arrow A).

Saliva includes many components that are derived from blood, because acinar cells produce saliva from blood

Correspondence to: Keiichi Tsukinoki, Department of Environmental Pathology, Graduate School, Kanagawa Dental College, 82, Inaoka, Yokosuka, Kanagawa 238-8580, Japan.

E-mail: ktsukino@kdcnet.ac.jp plasma. The identification of salivary products might reflect the status of systemic health or disease. Therefore, dentistry and other medical disciplines have started to search for biomarkers in saliva and to develop relevant laboratory tests (Fig. 1, arrow B).

Although the hormone-like effects of salivary gland products such as cell growth factors were investigated during the late 1980s and early 1990s [43], little is understood about the influence of the salivary gland on the entire body, and the functions in vivo of growth factors produced by the salivary gland have not yet been determined. However, since components produced by salivary glands are likely to enter the bloodstream by reabsorption from the duct and sublingual mucosa [3], salivary glands might contribute to both oral and total health. Thus, the potential hormone-like effects of such components on the whole body should be re-examined (Fig. 1, arrow C). The potential clinical roles of factors produced by the salivary gland should be investigated in detail.

We propose "salivary glands and health medicine" as a novel field of study. This concept includes elucidating 


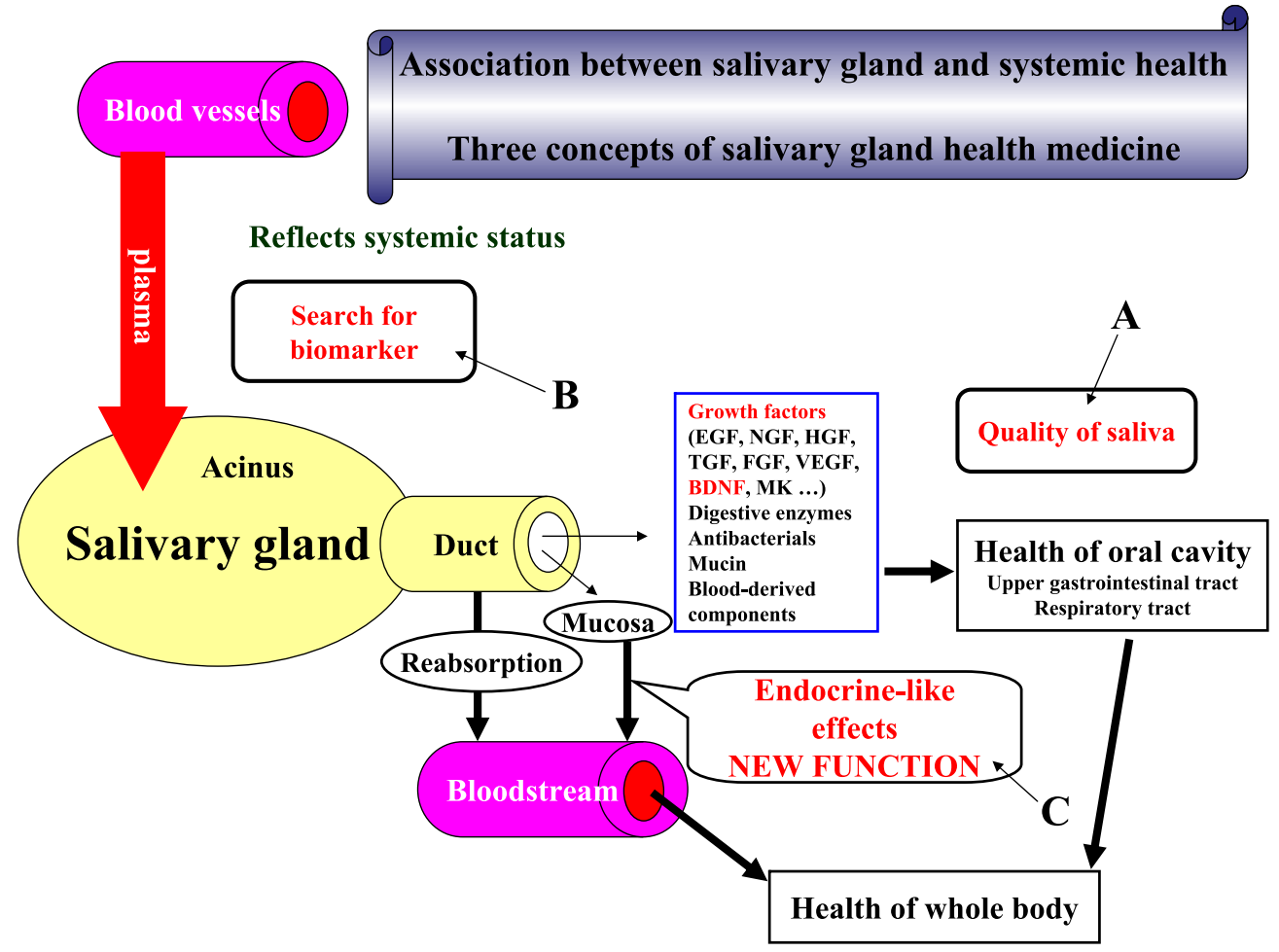

Fig. 1. Schema of the role of the salivary gland in health medicine. Important research concepts regarding salivary glands are shown.

the effects of the body on the salivary glands and the reciprocal effects of the salivary glands on the body, as well as the clinical applicability of laboratory tests of saliva (Fig. 1, arrow A-C). Especially, we reported regarding hormone-like effects of salivary gland in workshop of the 52nd annual meeting of the Japan Society of Histochemistry and Cytochemistry.

Salivary glands produce various cell growth factors, such as epidermal growth factor (EGF), nerve growth factor (NGF) and hepatocyte growth factor [39, 40]. In fact, EGF and NGF purified from the rat submandibular gland led to the acknowledgment of new salivary gland functions [8,9]. Mouse salivary gland tissues express high levels of NGF [3]. The NGF family consists of NGF, brain-derived neurotrophic factor (BDNF), and neurotrophins (NTs)-3, $-4 / 5,-6$, and -7 , all of which are collectively referred to as neurotrophins $[6,23,32]$. However, the expression of neurotrophins other than NGF in the salivary gland has not been analyzed. Immobilization stress reduces mRNA levels of neurotrophins such as NGF, BDNF, and NT-3 in the rat brain, especially in the hippocampus [44]. In contrast, NGF expression increases in response to stress in the mouse salivary gland [3]. The production of various cell growth factors often increases during episodes of stress to maintain homeostasis in the salivary gland [3]. We describe the relationship between hormone-like effects and stress-related BDNF expression of the rat submandibular gland in this review.

\section{What is BDNF?}

More BDNF (purified from pig brain) is expressed and it is more widely distributed than NGF in the central nervous system (CNS), where it acts as a trophic factor for dopaminergic and cholinergic neurons of the substantia nigra/ventral mesencephalon $[6,23]$. In addition to being retrogradely transported, BDNF that is anterogradely transported in the CNS acts as both a target-derived neurotrophic factor and an autocrine/paracrine modulator [4]. Furthermore, BDNF plays an important role in long-term synapse potentiation [18]. The amount of BDNF expressed in the hippocampus varies depending on the amount of stress [13], stress plus biting behavior [22], exercise [1] and learning [11], and it plays an important role in facilitating the formation of neural networks. On the other hand, the lachrymal glands [13], lymphocytes [36], vascular endothelial cells [24] and salivary glands of rats [30, 31] and humans [33] express BNDF. BDNF may play important roles in the various organs except for CNS.

\section{Salivary BDNF Expression Increases under Acute Stress}

Male Sprague-Dawley rats aged 7-9 weeks (Japan SLC, Shizuoka, Japan) were immobilized using a stress model according to an established protocol [17] that rapidly induces ACTH and corticosterone [13]. We previously demonstrated increased BDNF mRNA and protein expres- 


\section{Immobilization}

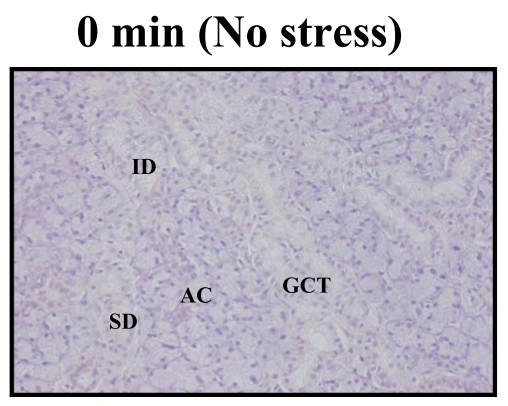

$60 \mathrm{~min}$

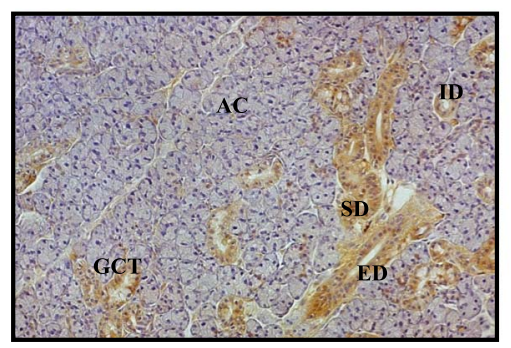

$30 \mathrm{~min}$

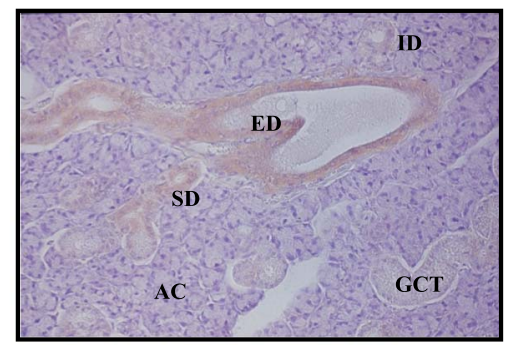

$180 \mathrm{~min}$

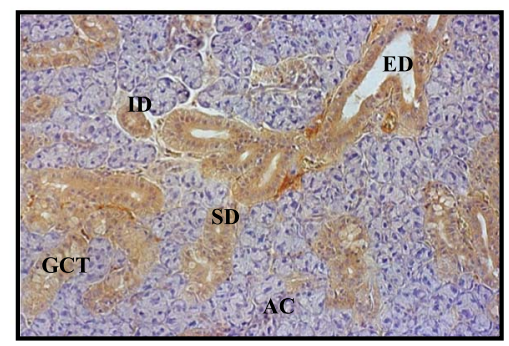

Fig. 2. Immunohistochemical localization of BDNF in male rat submandibular gland following immobilization stress. Immunohistochemical localization of BDNF protein in paraffin-embedded tissues from stressed rats using anti-BDNF monoclonal antibody $(n=6)$. Duct cells express BDNF protein (original magnification, $\times 100)$. AC, acinar cells; ED, excretory ducts; GCT, granular convoluted tubule; ID, intercalated ducts; SD, striated ducts (modified from Tsukinoki et al., 2006).

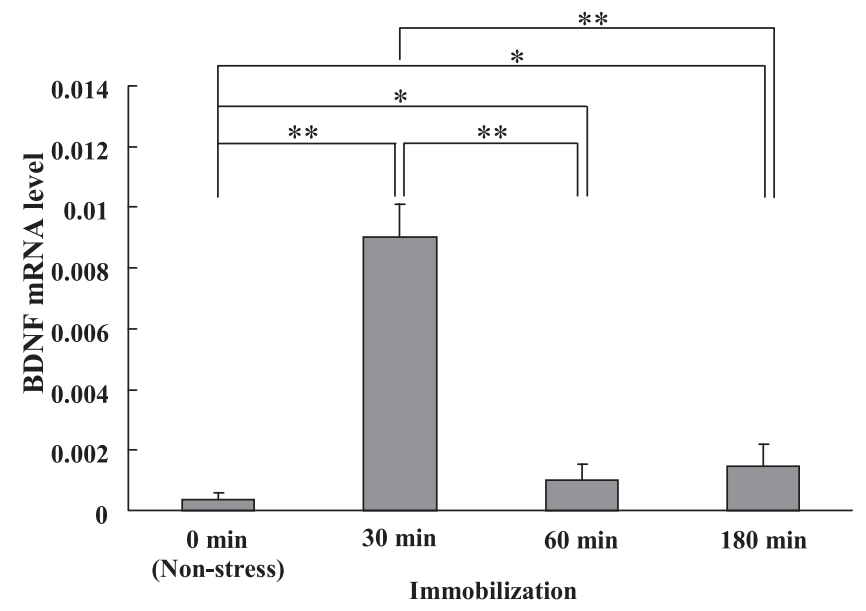

Fig. 3. Effect of immobilization stress on BDNF mRNA levels in rat submandibular gland. Levels of BDNF mRNA determined in rat submandibular gland using quantitative RT-PCR. Data are BDNF/ $\beta$-actin mRNA ratios. Graph of BDNF mRNA in stressed rats shows significant differences between non-stress and at 30 , 60 or $180 \mathrm{~min}$ of stress. Values are means \pm SEM; $n=6$ rats per group. ${ }^{*} \mathrm{p}<0.05, * * \mathrm{p}<0.01$, ANOVA/Tukey's test (modified from Tsukinoki et al., 2006).

sion in rat submandibular gland tissue using this model [41]. Ernfors et al. [12] originally described BDNF expression in rat submandibular gland tissue in the absence of stress, but BDNF mRNA was not detected by in situ hybridization (ISH) with an oligonucleotide probe [12]. Our findings under non-stressed conditions were consistent with these (Fig. 2). The imposition of acute immobilization stress resulted in BDNF protein becoming localized to the rat ductal epithelium including stratified and granular duct

\section{Immobilization}

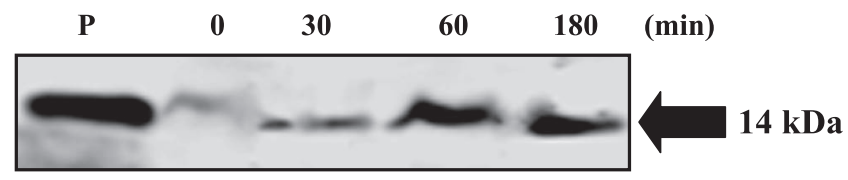

Fig. 4. Effects of immobilization stress on BDNF protein levels in rat submandibular gland. Western blots of BDNF expression in equal amounts of total protein from submandibular glands of control and stressed rats show $14 \mathrm{kDa}$ bands in brain and submandibular gland of stressed rats $(n=6)$. P, Positive control (brain tissue) (from Tsukinoki et al., 2006).

cells (Fig. 2). Levels of BDNF mRNA (Fig. 3) and protein (Fig. 4) in the submandibular gland significantly increased in stressed rats compared with non-stressed rats [41]. Levels of BDNF mRNA notably increased in rats that were immobilized for $30 \mathrm{~min}$ (Fig. 3). The microdissection of cells that were BDNF-immunofluorescence positive combined with quantitative RT-PCR revealed BDNF protein and mRNA localization in the ductal epithelium of rat submandibular glands (Fig. 5). These findings indicated associations between morphological findings and BDNF mRNA expression, and suggested that the salivary gland is sensitive to stress. That is, the submandibular gland responds to stress by expressing more BDNF.

\section{Expression of TrkB in the Submandibular Gland under Acute Stress}

BDNF interact with high-affinity protein kinase receptors for the tyrosine receptor kinase (Trk) family $[5,36]$, 
Immobilization (60 min)

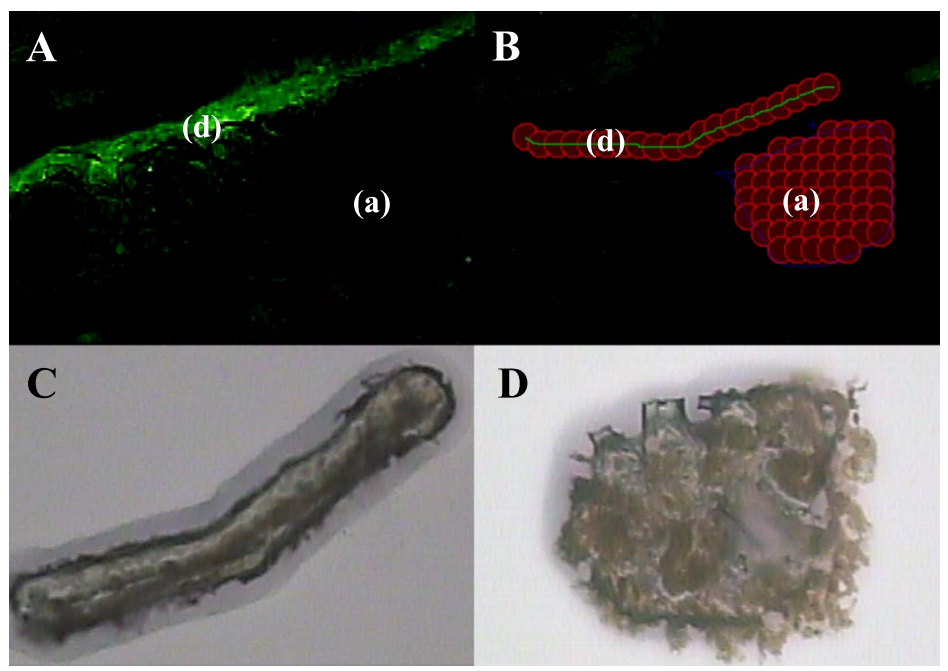

$\mathbf{E}$

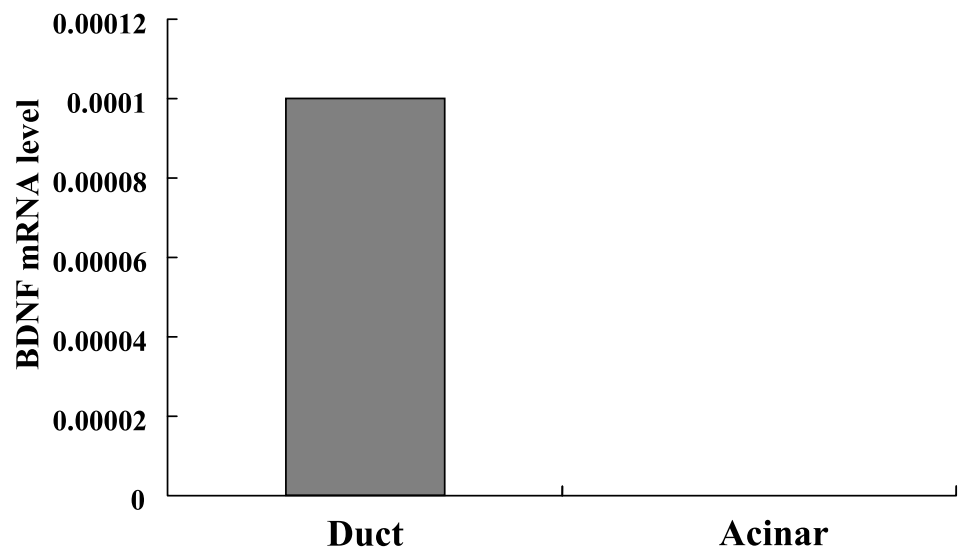

Fig. 5. Microdissection analysis of BDNF mRNA and protein expression in rats after immobilization stress for $60 \mathrm{~min}$. (A) Immunofluorescence staining identified BDNF reactivity within duct, but not acinar cells (original magnification, $\times 200$ ). (a) Acinar cells. (d) Duct cells. (B) Duct and acinar cells dissected from tissue sections (original magnification, $\times 200$ ). (a) Acinar cells. (d) Duct cells. (C) Cap image shows dissected duct cells (original magnification, $\times 400$ ). (D) Cap image shows dissected acinar cells (original magnification, $\times 400$ ). (E) Levels of BDNF mRNA in rat submandibular gland measured using quantitative RT-PCR. Graph shows BDNF/ $\beta$-actin ratios of dissected samples. Levels of BDNF mRNA in duct and acinar cells are 0.0001 and 0 , respectively. Duct, but not acinar cells express BDNF mRNA (modified from Tsukinoki et al., 2006). particularly the TrkB receptor [5]. Notably, RT-PCR did not detect TrkB mRNA in the submandibular gland, in the oral or esophageal mucosa in non-stressed rats, and in time-course stress studies despite increased BDNF mRNA and protein expression (Fig. 6A and B) [41]. Others have also shown that TrkB is not expressed in human salivary glands [10] or in esophageal mucosa [35] in the absence of stress. Thus, BDNF derived from the submandibular gland might act at distant sites after release into the bloodstream.

\section{Association of Plasma BDNF and Salivary Glands}

The salivary glands release NGF into the bloodstream after stress induced by fighting [2, 3], and serum and brain BDNF protein levels positively correlate [19]. However, serum BDNF is unlikely to affect the CNS, since serum BDNF is derived from intact platelets [45]. Rat plasma contains low levels of free BDNF [27]. Since BDNF can cross the blood-brain barrier [26], the effects of free plasma BDNF on the central nervous system might be more significant than those of serum of BDNF. Although traumainduced changes in neurotrophins and their receptors within the central nervous system might protect against neuronal damage [14], free plasma BDNF might contribute to recovery from a decrease of BDNF. However, the source and roles of plasma BDNF are poorly understood under the physiological conditions.

Plasma BDNF levels were significantly higher after stress for 60 and $180 \mathrm{~min}$ than in controls and after $30 \mathrm{~min}$ of stress (Fig. 7) [42]. Thus, we confirmed that acute immobilization stress increases plasma BDNF levels. Elevated plasma BDNF protects against neural damage by methamphetamine [20]. However, a decrease in plasma BDNF correlates with the severity of schizophrenia accompanied by tardive dyskinesia, indicating that a reduction in neural cell protection elicited by BDNF is responsible for the tardive dyskinesia $[15,29]$. In addition, since BDNF can pass through the blood-brain barrier [26], free BDNF entering the plasma (endogenous BDNF) might protect neural cells and maintain their functions. Therefore, an increase in plasma BDNF might help to protect cells against damage caused by acute stress at the early stages.

Removing the salivary glands (sialoadenectomy) suppressed the increase in plasma BDNF at 60-min of stress (Fig. 8) [42]. However, since the suppression was partial in 
A

Immobilization (min)

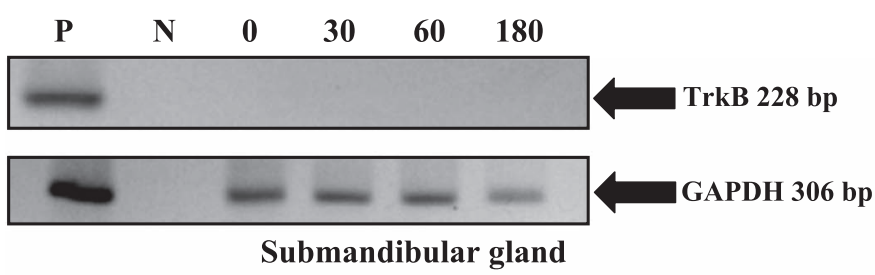

C

Immobilization (min)

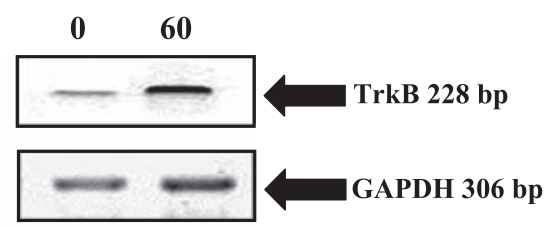

B

Immobilization (min)
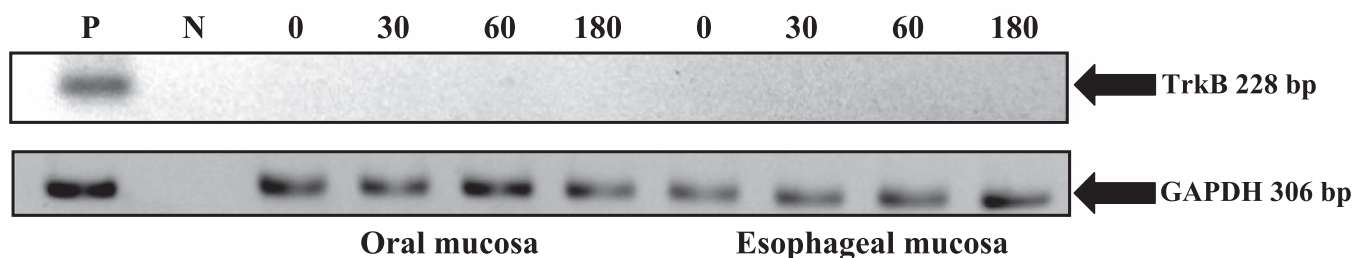

Fig. 6. Effects of immobilization stress on TrkB mRNA expression in rats. Levels of TrkB mRNA in rat tissues were investigated using conventional RT-PCR. (A) Submandibular gland tissue. (B) Oral and esophageal mucosa. TrkB mRNA was detectable only brain tissue. (C) Adrenal gland tissue. P, Positive control (brain tissue); N, Negative control (DNase/RNase-free deionized, distilled water); 0, no stress; 30, 60, 180, immobilization stress for 30,60, and $180 \mathrm{~min}$, respectively (modified from Tsukinoki et al., 2006).

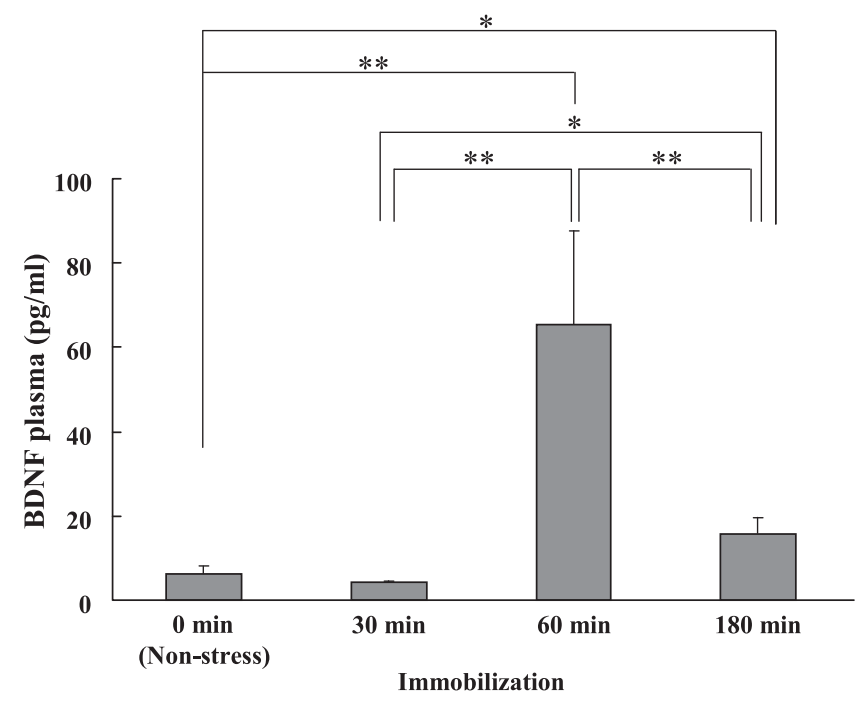

Fig. 7. Plasma BDNF levels following immobilization stress. Plasma BDNF concentrations assayed using ELISA kits. Values are means \pm SEM.; $\mathrm{n}=6$ rats per group. Significant differences: ${ }^{*} \mathrm{p}<0.05$, $* * \mathrm{p}<0.001$ ANOVA/Tukey's test (modified from Tsukinoki et al., 2007).

sialoadenectomized rats, we investigated BDNF expression in the rat heart, lungs [37], liver [7], pancreas [16], and spleen [34], as they might be associated with peripheral BDNF. The expression of BDNF mRNA in these organs did not significantly increase with immobilization [42]. A previous study found increased BDNF mRNA and protein expression in the pituitary glands of rats exposed to acute

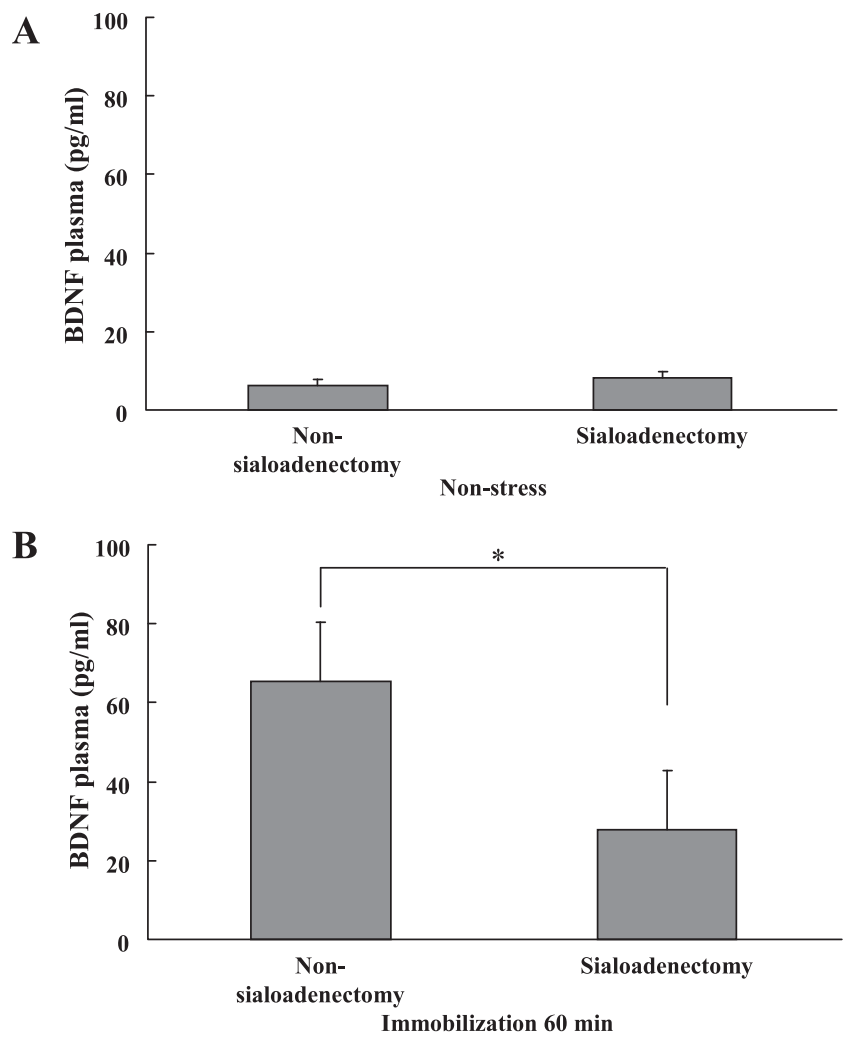

Fig. 8. Levels of BDNF protein in sialoadenectomized rats before and after acute immobilization stress. Plasma BDNF levels in nonstressed (A) and stressed (B) rats. Values are means \pm SEM.; $n=6$ rats per group. Significant difference, ${ }^{*} \mathrm{p}<0.05$ Student's t-test (modified from Tsukinoki et al., 2007). 


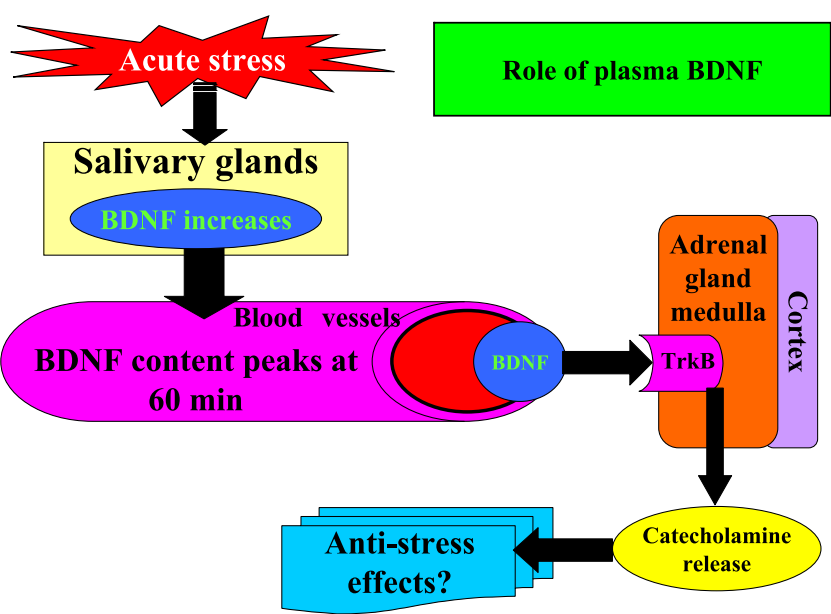

Fig. 9. Possible roles of stress-induced BDNF production by salivary glands. Stress-related salivary BDNF transits from salivary gland to bloodstream. Plasma BDNF derived from salivary gland circulates and binds to TrkB in adrenal medulla where TrkB activation induces catecholamine release.

immobilization stress for $60 \mathrm{~min}$ [13]. The pituitary gland produces various hormones and thus might also release BDNF into the bloodstream. If so, then not only the salivary gland but also the pituitary gland influences plasma BDNF during acute immobilization stress. However, we speculate that the submandibular glands are the primary source of plasma BDNF during acute immobilization stress, because plasma BDNF increased more in non-sialoadenectomized rats than in sialoadenectomized rats. In addition, the submandibular gland might release salivary BDNF into the bloodstream in response to acute immobilization stress.

\section{Role of Plasma BDNF in the Adrenal Gland}

We previously described several novel findings regarding the role of $\mathrm{BDNF}$ and its receptor TrkB during immobilization stress [21]. Firstly, levels of TrkB mRNA in organs including the cerebral cortex, hippocampus, lung, stomach, liver, pancreas, kidney, pituitary gland and adrenal gland were determined by real-time PCR using a primer set that recognizes the TrkB extracellular domain (pan-TrkB). We found that acute immobilization stress for $60 \mathrm{~min}$ did not affect TrkB mRNA expression in the cerebral cortex, hippocampus, lungs, stomach, liver, pancreas and kidneys. In contrast, TrkB mRNA expression in the pituitary and adrenal glands was modified and TrkB receptor expression was maximally increased at $60 \mathrm{~min}$ of stress in the adrenal medulla compared with that in the absence of stress (Fig. 6C). Secondly, plasma BDNF might activate TrkB receptors of the adrenal medulla during acute stress. Thirdly, BDNF directly induces the release of catecholamines from PC12 cells [25] derived from chromaffin cells of the rat adrenal medulla by activation of TrkB-T1 receptors. Thus, BDNF-TrkB interactions might modulate catecholamine release from adrenal chromaffin cells under acute stress (Fig. 9).

\section{Conclusion}

The expression of BDNF was increased in the submandibular glands of rats under acute immobilization stress, and contributed to increased plasma BDNF levels. The increase in the plasma BDNF concentration was significantly greater in non-sialoadenectomized rats than in sialoadenectomized rats. Thus, we demonstrated that the rat submandibular glands are the major source of plasma BDNF under acute immobilization stress. Furthermore, TrkB receptor expression was increased under acute stress and peaked at $60 \mathrm{~min}$ of stress in the adrenal medulla compared with levels under non-stressed conditions. Further studies should investigate BDNF-TrkB interactions in organs including the brain, and not simply focus on the adrenal gland that expresses high levels of TrkB.

\section{Acknowledgments}

The author is grateful to Professor Osamu Amano and Dr. Shōjiro Morinaga for the invitation to this workshop. This study was supported in part by Kakenhi a Grant-in-Aid for Scientific Research (B, \#23390420) from the Japan Society for the Promotion of Science.

\section{References}

1. Adlard, P. A. and Cotman, C. W. (2004) Voluntary exercise protects against stress-induced decreases in brain-derived neurotrophic factor protein expression. Neuroscience 124; 985-992.

2. Alleva, E. and Francia, N. (2009) Psychiatric vulnerability: suggestions from animal models and role of neurotrophins. Neurosci. Biobehav. Rev. 33; 525-536.

3. Aloe, L., Alleva, E., Böhm, A. and Levi-Montalcini, R. (1986) Aggressive behavior induces release of nerve growth factor from mouse salivary gland into bloodstream. Proc. Natl. Acad. Sci. US A 83; 6184-6187.

4. Altar, C. A. and DiStefano, P. S. (1998) Neurotrophin trafficking by anterograde transport. Trends Neurosci. 21; 433-437.

5. Barbacid, M. (1994) The Trk family of neurotrophin receptors. J. Neurobiol. 25; 1386-1403.

6. Barde, Y. A., Edgar, D. and Thoenen, H. (1982) Purification of a new neurotrophic factor from mammalian brain. $E M B O \mathrm{~J} .1$; 549-553.

7. Cassiman, D., Denef, C., Desmet, V. J. and Roskams, T. (2001) Human and rat hepatic stellate cells express neurotrophins and neurotrophin receptors. Hepatology 33; 148-158.

8. Chohen, S. (1960) Purification of a nerve-growth promoting protein from the mouse salivary gland and its neuro-cytotoxic antiserum. Proc. Natl. Acad. Sci. US A 46; 302-311.

9. Chohen, S. (1962) Isolation of a mouse submaxillary gland protein accelerating incisor eruption and eyelid opening in the newly born animal. J. Biol. Chem. 237; 1555-1562.

10. De Vincente, J. C., Garcia-Suárez, O., Esteban, I., Santamaria, J. and Vega, J. A. (1998) Immunohistochemical localization of neurotrophins and neurotrophin receptors in human and mouse salivary glands. Ann. Anat. 180; 157-163.

11. Egan, M. F., Kojima, M., Callicott, J. H., Goldberg, T. E., Kolachana, B. S., Bertolino, A., Zaitsev, E., Gold, B., Goldman, D., Dean, M., Lu, B. and Weinberger, D. R. (2003) The BDNF 
val66met polymorphism affects activity-dependent secretion of BDNF and human memory and hippocampal function. Cell 112; 257-269.

12. Ernfors, P., Wetmore, C., Olson, L. and Persson, H. (1990) Identification of cells in rat brain and peripheral tissues expressing mRNA for members of the nerve growth factor family. Neuron 5; 511-526.

13. Ghinelli, E., Johansson, J., Rios, J. D., Chen, L. L., Zoukhri, D., Hodges, R. R. and Dartt, D. A. (2003) Presence and localization of neurotrophins and neurotrophin receptors in rat lacrimal gland. Invest. Opthalmol. Vis. Sci. 44; 3352-3357.

14. Givalois, L., Marimigère, F., Rage, F., Ixart, G., Arancibia, S. and Tapia-Arancibia, L. (2001) Immobilization stress rapidly and differentially modulates BDNF and TrkB mRNA expression in the pituitary gland of adult male rat. Neuroendocrinology 74 ; $148-159$

15. Goto, F., Saruta, J., Kanzaki, S., To, M., Tsutsumi, T., Tsukinoki, K. and Ogawa, K. (2012) Various levels of plasma brain-derived neurotrophic factor in patients with tinnitus. Neurosci. Lett. 510; 73-77.

16. Hanyu, O., Yamatani, K., Ikarashi, T., Soda, S., Maruyama, S., Kamimura, T., Kaneko, S., Hirayama, S., Suzuki, K., Nakagawa, O., Nawa, H. and Aizawa, Y. (2003) Brain-derived neurotrophic factor modulates glucagons secretion from pancreatic alpha cells: Its contribution to glucose metabolism. Diabetes Obes. Metab. 5; 27-37

17. Hori, N., Lee, M. C., Sasaguri, K., Ishii, H., Kamei, M., Kimoto, K., Toyoda, M. and Sato, S. (2005) Suppression of stress-induced nNOS expression in the rat hypothalamus by biting. J. Dent. Res. $84 ; 624-628$

18. Kafitz, K. W., Rose, C. R., Thoenen, H. and Konnerth, A. (1999) Neurotrophin-evoked rapid excitation through TrkB receptors. Nature 401; 918-921.

19. Karege, F., Perret, G., Bondolfi, G., Schwald, M., Bertschy, G. and Aubry, J. M. (2002) Decreased serum brain-derived neurotrophic factor levels in major depressed patients. Psychiatry Res. 109; 143-148

20. Kim, Y. K., Lee, H. Y., Won, S. D., Park, E. Y., Lee, H. Y., Lee, B. H., Lee, S. W., Yoon, D., Han, C., Kim, D. J. and Choi, S. H. (2007) Low plasma BDNF is associated with suicidal behavior in major depression. Prog. Neuropsychopharmacol. Biol. Psychiatry. 31; 78-85.

21. Kondo, Y., Saruta, J., To, M., Shiiki, N., Sato, C. and Tsukinoki, K. (2010) Expression and role of the BDNF receptor-TrkB in rat adrenal gland under acute immobilization stress. Acta Histochem. Cytochem. 43; 139-147.

22. Lee, T., Saruta, J., Sasaguri, K., Sato, S. and Tsukinoki, K. (2008) Allowing animals to bite reverses the effects of immobilization stress on hippocampal neurotrophin expression. Brain Res. 1195; 43-49

23. Lewin, G. R. and Barde, Y. A. (1996). Physiology of the neurotrophins. Annu. Rev. Neurosci. 19; 289-317.

24. Nakahashi, T., Fujimura, H., Altar, C. A., Li, J., Kambayashi, J., Tandon, N. N. and Sun, B. (2000) Vascular endothelial cells synthesize and secrete brain-derived neurotrophic factor. FEBS Lett. 470; 113-117.

25. Nishida, T., Arii, T., Takaoka, A., Yoshimura, R. and Endo, Y. (2006) Three-dimensional, computer-tomographic analysis of membrane proteins (TrkA, caveolin, clathrin) in PC12 cells. Acta Histochem. Cytochem. 40; 93-99.

26. Pan, W., Banks, W. A., Fasold, M. B., Bluth, J. and Kastin, A. J. (1998) Transport of brain-derived neurotrophic factor across the blood-brain barrier. Neuropharmacology 37; 1553-1561.

27. Radka, S. F., Holst, P. A., Fritsche, M. and Altar, C. A. (1996) Presence of brain-derived neurotrophic factor in brain and human and rat but not mouse serum detected by a sensitive and specific immunoassay. Brain Res. 709; 122-130.

28. Saruta, J., Tsukinoki, K., Sasaguri, K., Ishii, H., Yasuda, M., Osamura, Y. R., Watanabe, Y. and Sato, S. (2005) Expression and localization of chromogranin A gene and protein in human submandibular gland. Cells Tissues Organs 180; 237-244.
29. Saruta, J., Sato, S. and Tsukinoki, K. (2010) The role of neurotrophins related to stress in saliva and salivary glands. Histol. Histopathol. 25; 1317-1330.

30. Saruta, J., Lee, T., Shirasu, M., Takahashi, T., Sato, C., Sato, S. and Tsukinoki, K. (2010) Chronic stress affects the expression of BDNF in rat salivary glands. Stress $13 ; 53-60$.

31. Saruta, J., Kondo, Y., Sato, C., Shiiki, N., Tsukinoki, K. and Sato, S. (2010) Salivary glands as the source of plasma brain-derived neurotrophic factor in stressed rats engaged in biting behavior. Stress 13; 238-247

32. Saruta, J., Iida, M., Kondo, Y., To, M., Hayashi, T., Hori, M., Sato, S. and Tsukinoki, K. (2012) Chronic stress induces neurotrophin-3 (NT-3) in the rat submandibular gland. Yonsei Med. J. (in press)

33. Saruta, J., Fujino, K., To, M. and Tsukinoki, K. (2012) Expression and localization of brain-derived neurotrophic factor (BDNF) mRNA and protein in human submandibular gland. Acta Histochem. Cytochem. (in press).

34. Schuhman, B., Dietrich, A., Sel, S., Hahn, C., Klingenspor, M., Lommatzsch, M., Gudermann, T., Braun, A., Renz, H. and Nockher, W. A. (2005) A role brain-derived neurotrophic factor in B cell development. J. Neuroimmunol. 163; 15-23.

35. Shibayama, E. and Koizumi, H. (1996) Cellular localization of the Trk neurotrophin receptor family in human non-neuronal tissues. Am. J. Pathol. 148; 1807-1818.

36. Sobue, G., Yamamoto, M., Doyu, M., Li, M., Yasuda, T. and Mitsuma, T. (1998) Expression of mRNAs for neurotrophins (NGF, BDNF, and NT-3) and their receptors (p75 NGFR, trk, trkB, and trkC) in human peripheral neuropathies. Neurochem. Res. 23; 821-829.

37. Timmusk, T., Palm, K., Metsis, M., Reintam, T., Paalme, V., Saarma, M. and Persson, H. (1993) Multiple promoters direct tissue-specific expression of the rat BDNF gene. Neuron 10; 475489.

38. Tsukinoki, K., Yasuda, M., Asano, S., Karakida, K., Ota, Y., Osamura, R. Y. and Watanabe, Y. (2003) Association of hepatocyte growth factor expression with salivary gland tumor differentiation. Pathol. Int. 53; 815-822.

39. Tsukinoki, K., Suzuki, K., Hori, M., Karakida, K., Yasuda, M., Asano, S. and Watanabe, Y. (2004) The role of cell growth factors in saliva salivary glands and salivary gland tumors. Bull. Kanagawa Dent. Col. 32; 63-67.

40. Tsukinoki, K., Yasuda, M., Miyoshi, Y., Mori, Y., Ootsuru, M., Saruta, J., Sato, S., Kaneko, A., Watanabe, Y. and Osamura, Y. (2005) Role of hepatocyte growth factor and c-Met receptor in neoplastic conditions of salivary glands. Acta Histochem. Cytochem. 38; 25-30

41. Tsukinoki, K., Saruta, J., Sasaguri, K., Miyoshi, Y., Jinbu, Y., Kusama, M., Sato, S. and Watanabe, Y. (2006) Immobilization stress induces BDNF in rat submandibular glands. J. Dent. Res. 85; 844-848.

42. Tsukinoki, K., Saruta, J., Muto, N., Sasaguri, K., Sato, S., TanIshii, N. and Watanabe, Y. (2007) Submandibular glands contribute to increases in plasma BDNF levels. J. Dent. Res. 86; 260264.

43. Tsukinoki, K., Saruta, J., Yamano, S. and Tomita, M. (2011) The salivary gland and systemic health: Towards the creation of salivary grand and health medicine. J. Oral Biol. 53; 330-337.

44. Ueyama, T., Kawai, Y., Nemoto, K., Sekimoto, M., Tone, S. and Senba, E. (1997) Immobilization stress reduced the expression of neurotrophins and their receptors in the rat brain. Neurosci. Res. 28; 103-110.

45. Yamamoto, H. and Gurney, M. E. (1990) Human platelets contain brain-derived neurotrophic factor. J. Neurosci. 10; 3469-3478

This is an open access article distributed under the Creative Commons Attribution License, which permits unrestricted use, distribution, and reproduction in any medium, provided the original work is properly cited. 